\title{
I 05 I Comparison of contrast and non-contrast 3-dimensional magnetic resonance angiography techniques for evaluation of the thoracic aorta
}

\author{
Monvadi B Srichai*, Sooah Kim, Leon Axel, James S Babb and \\ Elizabeth M Hecht
}

Address: NYU School of Medicine, New York, NY, USA

* Corresponding author

from I th Annual SCMR Scientific Sessions

Los Angeles, CA, USA. I-3 February 2008

Published: 22 October 2008

Journal of Cardiovascular Magnetic Resonance 2008, I0(SuppI I):AI76 doi:I0.I I86/I532-429X-I0-SI-AI76

This abstract is available from: http://jcmr-online.com/content/I0/SI/AI76

(C) 2008 Srichai et al; licensee BioMed Central Ltd.

\section{Introduction}

Contrast enhanced magnetic resonance angiography (CEMRA) has become a first-line investigation for the initial assessment and follow-up of thoracic aortic disease. However, recognized limitations with conventional CE-MRA include longer imaging times when compared to CT, the presence of motion artifacts, particularly at the aortic root, and the need for intravenous gadolinium-containing contrast agents which although fairly safe, have recently been associated with potentially significant toxic effects, particularly in patients with pre-existing renal disease.

\section{Purpose}

We hypothesize that non-contrast 3D true FISP MRA (NCMRA) of the thoracic aorta offers similar, if not superior, image quality compared to CE-MRA.

\section{Methods}

NC-MRA and 3D FLASH CE-MRA were performed on 21 patients $(M=18$, mean age $=51 \mathrm{y})$ with suspected thoracic aortic disease. Examinations were performed at $1.5 \mathrm{~T}$ (Avanto, Siemens) with a multichannel phased-array coil and parallel imaging $(\mathrm{R}=2)$. NC-MRA was performed with ECG and respiratory gating. CE-MRA was performed after injection of $0.1 \mathrm{mml} / \mathrm{kg}$ Gd-DTPA at $2 \mathrm{~mL} / \mathrm{sec}$ after appropriate scan delay. Field of view and matrix size were adjusted for each patient, but were similar between the two sequences. Data sets were retrospectively reviewed by 2 readers blinded to patient information. Aortic dimen- sions were measured at standard sites including the sinus, sinotubular junction, mid ascending, transverse arch, mid descending and diaphragmatic levels. For evaluation of image quality (IQ), the thoracic aorta was divided into 5 segments (root, ascending, arch, descending, great vessel origins). IQ was rated on a 5 point scale ( $1=$ uninterpretable, $2=$ poor, $3=$ satisfactory, $4=$ good, $5=$ excellent $)$ based on visualization of aortic wall, coronary artery origins and artifacts. Confidence was scored on a 5 point ordinal scale. Signal-to-noise ratio (SNR) was calculated for each study. Wilcoxon matched-pairs signed rank test was used for comparison of categorical variables and student's t-test was used for continuous variables.

\section{Results}

MRA findings in 21 subjects diagnosed on both techniques included: aneurysm (3), dissecting aneurysm (2), coarctation (1), atheroma (3), no significant disease (12). There were no significant differences in the measurement of the aortic dimensions at the mid ascending, arch, mid descending or diaphragm levels between the two techniques. However, mean luminal diameter and area measurements were significantly higher for NC-MRA compared to CE-MRA at the level of the aortic sinus $(34.6 \mathrm{~mm}$ versus $33.7 \mathrm{~mm}$ and $9.6 \mathrm{~cm} 2$ versus $9.1 \mathrm{~cm} 2, \mathrm{p}<0.05)$ and sinotubular junction $(30.6 \mathrm{~mm}$ versus $29.7 \mathrm{~mm}$ and $7.5 \mathrm{~cm} 2$ versus $7.1 \mathrm{~cm} 2, \mathrm{p}<0.01)$. Overall IQ was improved with the NC-MRA compared to CE-MRA technique (mean IQ score: 4.2 versus $4.1, \mathrm{p}=\mathrm{NS}$ ). This improved IQ was pre- 
dominantly related to higher IQ observed in the aortic $\operatorname{root}(4.4 \pm 0.8$ versus $3.2 \pm 0.9, \mathrm{p}<0.0005)$ and ascending aorta $(4.1 \pm 1.0$ versus $3.7 \pm 0.9, \mathrm{p}=0.05)$ for NC-MRA compared to CE-MRA. Both coronary artery origins were seen in 16 subjects on NC-MRA and only 1 subject on CEMRA. SNR was 64.2 for NC-MRA and 142.9 for CE-MRA. Mean reader confidence scores were similar (4.2) for both techniques.

\section{Conclusion}

NC-MRA provided better visualization of aortic root, ascending aorta, and coronary arteries, likely related to the use of cardiac gating with this technique. There was no significant difference in overall IQ and confidence between two techniques. NC-MRA using respiratory and ECG gated True FISP may be a potential alternative to CE-MRA for screening and follow up of thoracic aorta disease especially in patients with poor IV access or contraindications to gadolinium contrast.
Publish with Biomed Central and every scientist can read your work free of charge

"BioMed Central will be the most significant development for disseminating the results of biomedical research in our lifetime. " Sir Paul Nurse, Cancer Research UK

Your research papers will be:

- available free of charge to the entire biomedical community

- peer reviewed and published immediately upon acceptance

- cited in PubMed and archived on PubMed Central

- yours - you keep the copyright

Submit your manuscript here:

http://www.biomedcentral.com/info/publishing_adv.asp 